\title{
Do People Vote on the Basis of Minimax Regret?
}

ANDRÉ BLAIS, UNIVERSITÉ DE MONTRÉAL

ROBERT YOUNG, UNIVERSITY OF WESTERN ONTARIO

CHRISTOPHER FLEURY, UnIVERSTTY OF Michigan, DeARborn

MIRIAM LAPP, UNIVERSITÉ DE MONTRÉAL

\begin{abstract}
Rational choice theory has yet to provide a satisfactory explanation of voter turnout. One such account, minimax regret, is analyzed using data from a survey involving students at two Canadian universities during the 1993 Canadian federal election campaign. While the minimax regret hypothesis is supported at the bivariate level, it fails to pass a multivariate test in which other components of the calculus of voting are included. Minimax regret appears to be little more than a rationalization on the part of those having a strong sense of duty to vote.
\end{abstract}

Students of rational choice theory are well aware of its historic inability to give a satisfactory account of even minimal participation in elections by rational, self-interested actors. This problem has been identified as the "paradox of voting"(Mueller 1989). The original calculus of voting, first developed by Downs (1957) and further elaborated by Riker and Ordeshook (1968), expresses the rewards for voting ( $R$ ) as: $R=B P-C$, where $B$ is the difference in utility (or benefits) an individual expects to receive if the preferred candidate defeats opponents with different characteristics; $\mathrm{P}$ is the probability that the individual will, by voting, bring about the victory of the preferred candidate; and $C$ is the cost to the individual of the act of voting. Because the probability term is extremely small in most cases, the model predicts abstention. Obviously, such a prediction is problematic because large numbers of citizens do vote.

The paradox was clear to Downs, and to Riker and Ordeshook, who attempted to reconcile rational assumptions and real behavior by incorporating into the original calculus consumption benefits, or utility derived from the act of voting itself. The decision to vote thus became expressed as: $\mathrm{R}=\mathrm{BP}-\mathrm{C}$ $+\mathrm{D}$, with $\mathrm{D}$ representing such psychic goods as helping save democracy, fulfilling a sense of civic duty, expressing one's efficacy, and so on (Riker and Ordeshook 1968: 28). But this solution works all too well. Because the BP term remains quite small, the voting calculus is reduced essentially to $R=D$ - C (Strom 1975: 909). This risks divorcing the decision to vote from the 
particulars of specific elections, making it dependent upon long-standing psychological predispositions. As Barry (1970) points out, if people vote because they feel they have a duty to vote, it is not clear at all that rational choice theory offers much substantive explanation of turnout (see also Green and Shapiro 1994: 68-69).

Ferejohn and Fiorina attempt to provide "one means of rescuing rational choice theorists from this embarrassing predicament" (1974: 525). They substitute a minimax regret decision strategy for the utility maximization calculus. Instead of voters making probabilistic assessments of expected utility, as in an investment decision, Ferejohn and Fiorina suggest that voters cannot assign probabilities to outcomes under uncertainty; so they calculate their possible losses or regrets under different strategies, and may choose the one that minimizes their maximum regret. This model predicts more turnout than does the strict utility maximization calculus. This is essentially because regret would be high were one's preferred candidate to lose by a single vote simply because one did not go to the polls. The potential voter has an incentive to minimize this maximum possible regret. The cost of voting would remain a disincentive, but in this model individuals would vote in greater numbers than would probabilistic utility-maximizers.

The most common critique of minimax regret concerns its assumption that voters operate under conditions of complete uncertainty and that they do not or cannot estimate probabilities (see Strom 1975; Stephens 1975; Mayer and Good 1975; Beck 1975; and Aldrich 1993). Such an assumption immediately strikes one as being intuitively implausible; even if voters cannot estimate the precise probability of various electoral outcomes, they are surely capable of figuring out that it is extremely unlikely that their favorite candidate will win or lose by a single vote.

The minimax regret model has also been criticized for being extremely conservative and for leading "to rather bizarre behavior when applied to other decisions or even when extended within the voting context" (Mueller 1989; 353). For example, it is commonly pointed out that the risk of injury or death in a car accident while traveling to and from the polls is at least as great as the risk of seeing one's preferred candidate lose by one vote (Beck 1975; Stephens 1975). The minimax regret model seems to imply that the regret to be derived from these two possible events is of comparable magnitude, and this is difficult to believe

The model thus suffers from serious theoretical difficulties. Ferejohn and Fiorina admit that it has weaknesses "as a prescriptive theory of decision making" (1975: 925). But rather than reject the model, they urge it be judged on its descriptive merits.

They propose a critical test. This involves seeing whether differences in perceived benefits (B) and perceived closeness (a proxy for $\mathrm{P}$ ) are significantly 
related to turnout. According to the Downsian theory, both B and P should be related to tumout: only when there is both an appreciable difference between candidates and an election perceived as close should rational electors turn out. According to minimax regret, only B matters because probabilities cannot be assigned ex ante to states of nature (Ferejohn and Fiorina 1975: 922). The choice between the two thus comes to rest on whether P (as measured by closeness) is significant. Using pre- and post-election surveys from the 1952 to 1964 presidential elections, Ferejohn and Fiorina find that the minimax regret hypothesis is supported five times out of seven, while the Downsian hypothesis is supported only once. While recognizing "the extreme crudeness" of their data and the "necessarily tentative nature of the empirical test" (1975: 923), they conclude that the model does have some descriptive merit.

A more direct test of the minimax regret model is offered by Kenney and Rice (1989). In a study carried out in two different cities, they asked respondents directly whether they made the minimax regret calculation. The specific question put was: "Please tell me whether you ever worry that if you don't vote your favorite candidate might lose by one vote-your vote" They find that over one-third of their respondents report having thought this at one time or another, thus qualifying as potential minimax regret decision-makers. Furthermore, they find that these minimax regret respondents are significantly more likely than others to report having voted in 1984 and to indicate an intention to vote in 1986. Finally, they compare minimax regret decision making with an index of expected utility and show that "the minimax variable differentiated between likely voters and nonvoters, while the expected utility index did not" (Kenney and Rice 1989: 159).

The studies by Ferejohn and Fiorina, and by Kenney and Rice, have substantial shortcomings. Ferejohn and Fiorina make only a most indirect test. They show only that the perceived closeness of an election is not related to turnout, which is inconsistent with the expected utility model. But this does not provide any concrete positive evidence in favor of minimax regret. The study by Kenney and Rice is more useful. It is descriptively interesting that at least one-third of the electorate report they have thought about the possibility that their favorite candidate could lose by one vote, and that such people are more likely to vote. The major limitation of the result is that the study does not explore other factors that may also explain turnout. The authors do not test whether minimax regret is still related to turnout when these other factors are controlled.

One study that does examine the minimax hypothesis at the multivariate level is that of Dennis (1991). Using data collected in Wisconsin during the 1984 presidential campaign, Dennis finds that his minimax regret measure is 
statistically significant when modeled along with several other "rationalist" indicators, but drops out of the model when a number of "alienationist" (psychological) measures are added. It should be noted, however, that the minimax measure created by Dennis is an index consisting of three questions, one of which is in our view problematic. Dennis asked his respondents whether they agreed or disagreed with the statement, "I sometimes don't vote when the outcome of the election is not going to be close." There are two problems with the question. First, it is couched in the negative, and it is not clear what disagreeing with the statement means. Second, as noted, while perceived closeness should not be a consideration for minimax regret voters, it cannot be assumed that all those who are not affected by closeness necessarily operate with a minimax regret calculus. Consequently, Dennis' results concerning the non-impact of minimax regret remain problematic.

To summarize, there are paradoxical results about the minimax regret hypothesis. On the one hand, the hypothesis-and the operationalizations of it-are suspect on theoretical grounds. On the other, there seems to be some empirical support for it, though that support is rather crude. Together, the theoretical ambiguities and empirical gaps in the literature on minimax regret suggest that a more precise empirical test is called for. This is exactly the gap that our study is intended to fill. To that end, we analyze a new data set that allows us to control for other variables in order to determine whether at least some people decide, on the basis of a minimax regret calculus, not to abstain but to vote.

\section{The STUdY}

Our study was conducted among students in ten classes at two universities, the Université de Montréal and the University of Western Ontario. Students were administered questionnaires, before and after the October 25, 1993, Canadian federal election. ${ }^{1}$ This design has the strong advantage of allowing us to measure voting behavior ${ }^{2}$ in the election as well as pre-election and

\footnotetext{
${ }^{1}$ More specifically, five groups were administered two questionnaires during the campaign and one after the election, and five groups were administered only the postelection questionnaire. Because the cost of voting was measured before the election, the analysis that follows is confined to the five groups that were administered all three questionnaires and, more precisely, to those individuals in these groups who answered at least the second (campaign) and third (post-election) questionnaires. The study also involved an experiment, as three groups were exposed to a short lecture on the paradox of voting. For a full presentation of the research design, see Blais and Young 1994.

2 We are dealing with reported turnout, as we had no way of verifying whether respondents actually voted. Sixty-eight percent of the total sample and 74 percent of the sample examined in this study (which is confined to the five groups that were administered two
} 
post-election attitudes. The survey instrument included a wide range of questions tapping many dimensions of electoral behavior. There was in particular a section composed of fifteen statements about voting to each of which respondents were asked to indicate their degree of agreement or disagreement. Included in this set was our question tapping minimax regret. It reads as follows: "I would really feel terrible if I didn't vote and my candidate lost by one vote." Our minimax regret measure differs somewhat from the ones used by Kenney and Rice and by Dennis in that it encourages the respondent to think concretely in terms of the election at hand, rather than in the more vague terms elicited by asking "whether you ever worry ..." (Kenney and Rice 1989: 155) or "have you ever believed ..." (Dennis 1991: 47). Because it is more concrete, we believe ours provides a more stringent measure of the minimax regret criterion. It is also similar in tone to the original minimax regret statement put forward by Ferejohn and Fiorina, which was: "My God, what if I didn't vote and my preferred candidate lost by one vote? I'd feel like killing myself" (Ferejohn and Fiorina 1974: 535). While avoiding the extreme reference to suicide, our question does capture the sense of great regret that Ferejohn and Fiorina suggested voters might seek to avoid.

Considerable numbers of respondents agreed with the minimax statement: 33 percent strongly agreed, another 38 percent agreed, 14 percent disagreed, only 7 percent strongly disagreed, and another 7 percent did not know. The percentage of respondents in our panel who strongly agreed with the minimax regret statement is similar to the proportion who reported in the Kenney and Rice study that they worry that their favorite candidate might lose by one vote. Substantial numbers of people seem to think in terms akin to minimax regret.

Of course, the finding of widespread acceptance of the logic of minimax regret does not in itself prove that political participation is actually affected by this type of reasoning. Are people who strongly agree with the minimax regret statement more likely to vote? According to our data, this is indeed the case. Fully 90 percent of those who strongly agreed with the minimax regret statement voted in the 1993 election, compared to 63 percent of the other respondents. This is a strong result but it is only a bivariate relationship, and we must put the minimax regret hypothesis to the more stringent test of a multivariate analysis.

questionnaires during the campaign and one after the election) indicated they had voted. Overall turnout in the election was 70 percent. It would thus seem that turnout was not overreported by our respondents (turnout among students tends to be lower than average in Canada; see Pammett 1991: 40). This is partly because the response rate was very high and partly because the incentive to misreport is smaller in a self-administered questionnaire than in an interview (see Sudman and Bradburn 1987: 277; Dillman 1978: 62-63). 
The question is whether the minimax variable remains a significant predictor of 'voting if we also include the standard terms of the calculus of voting: $B$, $\mathrm{P}, \mathrm{C}$, and also D, the "consumption" benefit. The questions used to measure these terms, as well as coding information, are presented in the Appendix.

Table 1 shows the results of our multivariate LOGIT regression. We operationalize minimax regret in two different ways. In the first measure, minimax is a dummy variable that takes the value of 1 for those strongly agreeing with the minimax regret statement. The assumption is that one has to agree strongly with the statement in order to be counted as a potential minimax regretter. $^{3}$ The second measure is a five-category variable which varies progressively from 0 to 1 according to the strength of agreement or disagreement with the minimax regret statement (see the Appendix).

E Table 1

Multivariate Unit Analysis of Voting Turnout

\begin{tabular}{|c|c|c|c|c|}
\hline \multirow{2}{*}{$\frac{\text { Variable }}{\text { Minimax Regret }}$} & \multicolumn{2}{|c|}{ Coefficient } & \multicolumn{2}{|c|}{ Coefficient } \\
\hline & +.18 & $(.41)$ & -.04 & $(.56)$ \\
\hline Probability & +.07 & $(.89)$ & +.06 & $(.89)$ \\
\hline Benefits & +1.67 & $(.68)^{* *}$ & +1.75 & $(.68)^{* *}$ \\
\hline Cost & -2.56 & $(.66)^{* *}$ & -2.63 & $(.65)^{* *}$ \\
\hline Duty & +5.02 & $(1.00)^{* *}$ & +5.18 & $(1.00)^{* *}$ \\
\hline Constant & -3.48 & $(.86)^{* *}$ & -3.57 & $(.84)^{* *}$ \\
\hline-2 Log likelihood & 263.52 & & 263.76 & \\
\hline Pseudo $\mathrm{R}^{2}$ & .23 & & .23 & \\
\hline $\mathrm{N}$ & 314 & & 314 & \\
\hline
\end{tabular}

** significant at the 01 level (one-tailed test)

Table entries are regression coefficients, with standard errors indicated in parentheses. All variables were transformed to a 0 to 1 scale. In column 1 , minimax regret is a dummy variable that takes the value of 1 for those strongly agreeing with the minimax statement and 0 for all other respondents. In column 2 minimax is a five-category variable, in which strongly agree is given a score of 1 , agree a score of 67 , don't know a score of .5 , disagree a score of 33 and strongly disagree a score of 0 . For variable descriptions, refer to the Appendix.

As can be seen, our measure of probability is not significantly related to turnout. ${ }^{4}$ This would seem to confirm the earlier finding of Ferejohn and

${ }^{3}$ The reasoning is that the minimax regretter is highly risk-averse, seeking to avoid something awful-the preferred candidate losing by one vote - and that only someone strongly agreeing with the statement that "I would really feel terrible if I didn't vote and my candidate lost by one vote" would fit that description.

${ }^{4}$ The measure of $\mathrm{P}$ used in Table $\mathrm{l}$ is based on the perceived probability of casting a 
Fiorina, who took the nonrelationship between turnout and $\mathrm{P}$ as evidence of the failure of the Downsian expected-utility model. This, however, should not be taken to confirm the minimax regret hypothesis. As we see in Table 1, our direct measures of minimax regret are not significant predictors of turnout, once the other elements of the calculus are controlled for. Why does the zeroorder relationship between voting and minimax regret vanish in the multivariate regression? The basic reason is that there is a relatively strong correlation between minimax and sense of duty. ${ }^{5}$ Those who believe it is the duty of every citizen to vote are prone to say they would feel really terrible if they did not vote and their candidate lost by one vote. Of course they would feel terrible, because they feel a moral obligation to vote and they would have failed to do so. Respondents thus may agree with the minimax regret statement either because it appropriately reflects their risk aversion or because they feel a duty to vote and the minimax statement just provides another reason to vote; in the latter case, minimax regret appears to be a mere reflection of a generalized sense of duty. ${ }^{6}$ When we purge minimax regret of this rationalization component, as we do in Table 1 by controlling for sense of duty, not much is left in terms of explanatory power. ${ }^{7}$

decisive vote at the national level. We also tried perceived probability measured at the riding level, but it too proved to be non-significant. When each of these measures was used in a multiplicative model, the BP term also came out non-significant. We also had two measures of $\mathrm{B}$, for the riding and the national level. Only the latter had an impact on the vote and was included in the final regressions. We also ran OLS regressions, as well as separate regressions on our control and experimental groups, and obtained very similar results. Finally, regressing turnout on the campaign-period (pre-election) equivalents of the independent variables produced similar findings

5 The correlations are .43 and .44 respectively when minimax is a dummy and when we retain the full coding. Those who score high on the minimax variables also tend to perceive a high party differential; the correlations between $B$ and the two measures of mini$\max$ are .35 and .37 . It should be noted that when we ran regressions without the duty variable, a small but significant relationship between minimax and voting was observed. This would seem to indicate that although minimax is correlated with both duty and party differential, it is the rationalization effect from duty that is the most important.

${ }^{6}$ It seems less plausible that one would move from minimax regret to sense of duty. Minimax regret is a calculus through which one evaluates the benefits and costs of voting for oneself. As such there is no reason why a minimax regretter would conclude that voting is a moral obligation for all citizens, while it is perfectly logical for someone who feels everyone should vote to be concerned with the possibility that his/her candidate could lose because he/she did not vote.

${ }^{7}$ It could also be argued that duty emerges as more significant in Table 1 because it is more finely measured than minimax regret. The latter can take only two values in the first measure and five in the second while duty can have fifteen values, as it is based on three items, each with five possible scores. To check that possibility, we reran 


\section{Conclusion}

The minimax regret hypothesis has spurred a vigorous theoretical debate but very little empirical research. We set out to fill that gap in this study. Our findings are consistent with the handful of empirical studies that do exist, and that examine the bivariate relationship between minimax regret and voting. We found that a substantial number of our respondents strongly agreed with the minimax statement and that these respondents were more likely to vote. However, when we pursued this relationship at the more demanding level of multivariate analysis, it was found that the effects of minimax are insignificant when other factors are controlled. Hence, our findings would appear to confirm the skepticism of those who doubted the theoretical foundations of minimax. At the same time, by showing empirically that minimax has no independent effect on turnout, we seem to have negated Ferejohn and Fiorina's claim that minimax is at least defensible descriptively if not theoretically.

\section{Appendix: Questions and Coding Information}

\section{Minimax Regret}

Respondents were asked whether they strongly agreed, agreed, disagreed, or strongly disagreed with the following statement:

"I would feel really terrible if I didn't vote and my candidate lost by one vote."

The variable was operationalized in two different ways. In the first coding, those who strongly agreed were given a score of 1 , all others a score of 0 . In the second coding, "strongly agree" was given a score of 1 , "agree" a score of .67 , "don't know" a score of .5, "disagree" a score of .33, and "strongly disagree" a score of 0 .

\section{(B) Benefits}

"How important was it to you, personally, which (candidate/party) was going to win the election in (your riding/Canada as a whole)? Please indicate how important this was to you on a scale of 0 to 10 , where 10 means that which (candidate/party) was going to win in (your riding/Canada as a whole) made a very great difference to you, and 0 means that it made no difference at all?

The score given by the respondent was divided by 10 , so that the variable ranged from 0 to 1 .

equation 1 , using only the first duty item as a dummy variable. This did not affect the sults; that is, duty remained significant and minimax was still non-significant. 


\section{(C) Cost}

"How difficult do you think it would be for you to go and cast your vote?" The response categories were: "very easy," "easy," "difficult," and "very difficult." They were given the score of $0, .33, .67$, and 1 , respectively.

\section{(D) Duty}

Respondents were asked whether they strongly agreed, agreed, disagreed, or strongly disagreed with the following statements:

"It is the duty of every citizen to vote."

"In order to preserve democracy, it is essential that the great majority of citizens vote"

"It is important to vote, even if my party or candidate has no chance of winning."

On each question, "strongly agree" was given a score of 1, "agree" a score of .67 , "don't know" a score of .5, "disagree" a score of .33 , and "strongly disagree" a score of 0 . The duty score corresponds to the average score on these three questions. For the rationale behind this scale, see Blais and Young (1994).

\section{(P) Probability}

"What do you think the chances were, roughly, that your vote would determine which (candidate/party) would the election in (your riding/Canada as a whole)?"

Respondents could choose among eight possibilities, ranging from 1 chance in 10 to 1 chance in $100,000,000$. The variable was transformed to a 0 to 1 scale, " 1 chance in 10 " being given the score of 1 and " 1 chance in $100,000,000$ " being given the score of 0 .

\section{REFERENCES}

Abramson, P. R., J. H. Aldrich, P. Paolino, and D. W. Rhode. 1992. "Sophisticated Voting in the 1988 Presidential Primaries." American Journal of Political Science 86: 55-69.

Aldrich, J. H. 1993. "Rational Choice and Turnout." American Journal of Political Science 37: 246-78.

Barry, B. 1970. Sociologists, Economists, and Democracy. London: CollierMacmillan.

Beck, N. 1975. "The Paradox of Minimax Regret." American Political Science Review 69: 918.

Blais, A., and R. Young. 1994. "Does Public Choice Erode Public Spint? An Experiment in Rationality, Electoral Norms, and Voting Behavior' Paper presented at the annual meeting of the Public Choice Society, Austin, March 29. 
Cox, G. W., and M. C. Munger. 1989. "Closeness, Expenditures, and Turnout in the 1988 U.S. House Elections." American Political Science Review 83: 217-31.

Dennis, J. 1991. "Theories of Turnout: An Empirical Comparison of Alienationist and Rationalist Perspectives." In William Crotty, ed., Political Participation and American Democracy. New York: Greenwood Press.

Dillman, D. A. 1978. Mail and Telephone Surveys: A Total Design Method. New York: Wiley.

Downs, A. 1957. An Economic Theory of Democracy. New York: Harper \& Row. Ferejohn, J. A., and M. P. Fiorina. 1974. "The Paradox of Not Voting: A Decision Theoretic Analysis." American Political Science Review 68: 525-36.

1975. "Closeness Only Counts in Horseshoes and Dancing." American Political Science Review 69: 920-25.

Green, D. P., and I. Shapiro. 1994. Pathologies of Rational Choice Theory: A Critique of Applications in Political Science. New Haven: Yale University Press.

Kenny, P. J., and T. W. Rice. 1989. "An Empirical Examination of the Minimax Hypothesis." American Politics Quarterly 17: 153-62.

Mayer, L.S., and I.J. Good. 1975. "Is Minimax Regret Applicable to Voting Decisions?" American Political Science Review 69: 916-17.

Mueller, D.C. 1989. Public Choice II. New York: Cambridge University Press. Pammett, J. 1991. "Voting Turnout in Canada." In H. Bakvis, ed., Voter Turnout in Canada. Toronto: Dundurn.

Riker, W. H., and P. C. Ordeshook. 1968. "A Theory of the Calculus of Voting." American Political Science Review 62: 25-43.

Stephens, S. V. 1975. "The Paradox of Not Voting: A Comment." American Political Science Review 69: 914-15.

Strom, G. S. 1975. "On the Apparent Paradox of Participation: A New Proposal." American Political Science Review 69: 908-13.

Sudman, S., and N. M. Bradburn. 1987. Asking Questions: A Practical Guide to Questionnaire Design. San Francisco: Jossey-Bass.

Received: November 7, 1994

Accepted for Publication: March 6, 1995

Political Research Quarterly, Vol. 48, No. 4 (December 1995), pp. 827-836 